\title{
JCCC: Platform for Students, Clinicians and the Common People
}

\author{
Poonam Malhotra Kapoor ${ }^{1}$ \\ ${ }^{1}$ Department of Cardiac Anesthesia, Cardio Thoracic Centre, \\ All India Institute of Medial Sciences, New Delhi, India
}

J Card Crit Care TSS 2018;2:1-2

Editor-in-Chief, Journal of Cardiac Critical Care

Journal of Cardiac Critical Care (JCCC), affiliated to The Simulation Society (TSS) of India, is a journal in its initial years. The journal is biannual in frequency and started publishing from last year in 2017. The journal came into existence to educate budding students and researchers who are working with critical care patients suffering from cardiovascular diseases, familiarize practicing clinicians with the trending development in anesthesia, and critical care management of patients, and at the same time disseminate information to the general mass by serving as a knowledge base for those who are interested in gaining an understanding of the subject.

TSS decided to join hands with Thieme Medical and Scientific Publishers, India, as their publishing partner because of their expertise to publish journals in diverse clinical categories which are highly rated in their respective clinical categories (www.thieme.com/journals) and carry their unique digital and print appeal. The society is thankful to Thieme Medical and Scientific Publishers, India for the personalized care which the journal receives for article evaluation, content management, and promotion at both national and global levels.

In its very first year, the journal published two high profile issues addressing several topics in the subject category. The topics covered several aspects of cardiac critical care including multivalvular disease in Indian subcontinent, ${ }^{1}$ technique of three-dimensional (3D) printing using noninvasive approach, ${ }^{2}$ Left Ventricular Rupture, ${ }^{3}$ Coronary Artery Bypass Grafting, ${ }^{4}$ etc., besides publishing a special issue on Extracorporeal Membrane Oxygenation (ECMO) with topics ranging from significance of ECMO on poisoning, ${ }^{5}$ and a special article from Dr. Conrad on the journey and evolution of the ECMO technique. ${ }^{6}$ Several abstracts, displayed during the 2018 South West Asia Chapter of Extracorporeal Life Support Organization (SWAC ELSO) conference in New Delhi, were published in the special issue (-Fig. 1). The vision of the journal so far has been to highlight key areas in critical care of patients suffering from cardiovascular ailments and help

Address for correspondence

Poonam Malhotra Kapoor, MD, DNB, MNAMS, FIACTA (Hony), FTEE (Hony), FISCU (Hony), Professor, Cardiac

Anesthesia, Cardio Thoracic

Centre, All India Institute of Medial

Sciences, New Delhi, India (e-mail:

drpoonamaiims@gmail.com).

young clinicians and clinical researchers familiarize with evolving techniques and standard mode of practices.

During a recent event at All India Institute of Medical Sciences, New Delhi, the journal was recently endorsed by the Institute's Director, where he personally displayed a poster prepared by the marketing department of Thieme Medical and Scientific Publishers, India, highlighting JCCC and Journal of Neuroanesthesiology and Critical Care (JNACC). The JCCC was represented by myself as the Editor-in-Chief, whereas JNACC was represented by its Editor Prof. Girija Rath, and Thieme Medical and Scientific Publishers, India was represented by Dr. Sunny Duttagupta who has been a driving force behind both the journals (-Fig. 2).

The journal and the society want to encourage potential authors and investigators in the field of critical care to submit their original articles, reviews, short communications, and case

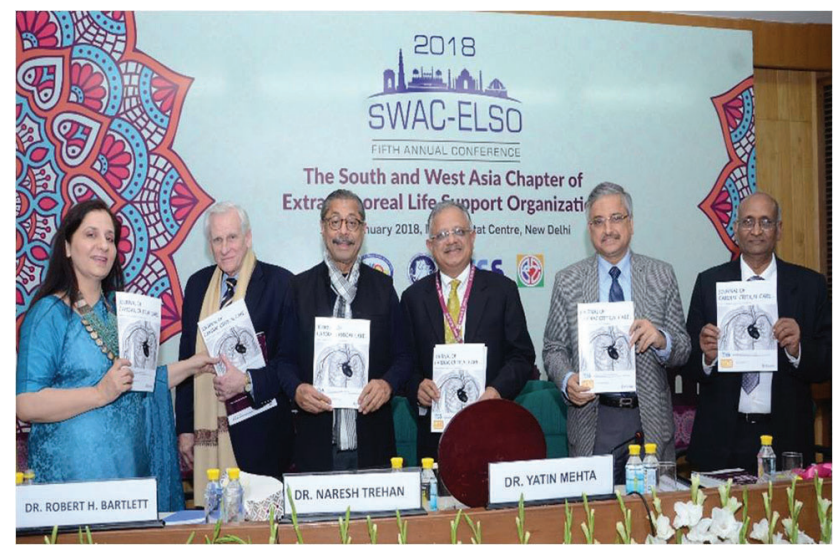

Fig.1 Inauguration of 2nd issue of Journal of Cardiac Critical Care at 2018 SWAC ELSO conference in New Delhi. From left to right: Prof. Poonam Malhotra Kapoor, Prof. A.I.I.M.S., New Delhi, Dept. Cardiac Anesthesia; Dr. Robert Bartlett, Prof. of Surgery, University of Michigan Medical Center; Dr. Naresh Trehan, Chairman and Managing Director Medanta; Dr. Yatin Mehta, Chairman, Dept. of Anesthesiology and Critical Care, Medanta; Prof. Randeep Guleria, Director A.I.I.M.S., New Delhi; and Prof. Balram Airan, exDean A.I.I.M.S., New Delhi. A.I.I.M.S., All India Institute of Medial Sciences; SWAC ELSO, South and West Asia Chapter of Extracorporeal Life Support Organization.

Copyright @2018 Official Publication of The Simulation Society (TSS), accredited by International Society of Cardiovascular Ultrasound (ISCU).
License terms

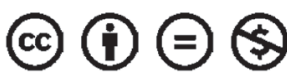

$10.1055 / \mathrm{s}-0038-1675502$

ISSN 2457-0206. 


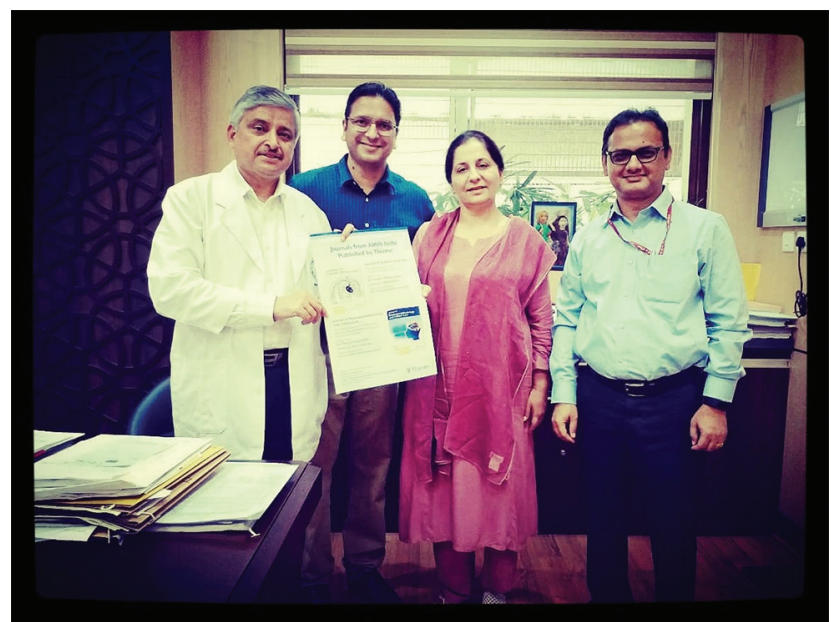

Fig. 2 Display of the journal poster at the Director Office, A.I.I.M.S., New Delhi. From left to right: Prof. Randeep Guleria, Director A.I.I.M.S., New Delhi; Dr. Sunny Duttagupta, Senior Acquisitions Editor, Thieme Medical and Scientific Publishers, India; Prof. Poonam Malhotra Kapoor, Editor-in-Chief, Journal of Cardiac Critical Care, Secretary and Chairman Academics - The Simulation Society; and Prof. Girija Rath, Editor, Journal of Neuroanesthesiology and Critical Care. A.I.I.M.S., All India Institute of Medial Sciences.

reports to the journal at www.manuscriptmanager.net/jccc. The journal follows rigorous double-blind peer review process and articles will be selected on the merit of the content.
In the upcoming days, the journal aims to conduct simulation based webinars, continuing medical educations (CMEs), and postgraduation assemblies on various topics of cardiac critical care to bring awareness of this important topic which will be made available to the target audience including the public, students, researchers, and clinicians.

\section{References}

1 Ladha S, Kapoor PM. Challenges in multivalvular heart disease: Indian scenario. J Card Crit Care 2017;1(1):15-20

2 Ahmad A, Nanda NC, Bartel T, McElwee S. Cardiac threedimensional printing using noninvasive modalities: will it revolutionize cardiac care? J Card Crit Care 2017;1(1):6-9

3 Raut MS, Maheshwari A, Dubey S, Shivnani G, Mohanty A, Makhija A. Left ventricular contained rupture: true or pseudoaneurysm? J Card Crit Care 2017;1(1):40-44

4 Kanchi M, Rudresh M, Das S. Continuous cardiac output measurement during off-pump coronary artery bypass grafting: radial arterial pulse wave versus femoral arterial pulse wave. J Card Crit Care 2017;1(2):95-100

5 Gupta V, Wander GS. ECMO in poisoning. J Card Crit Care 2017;1(2):82-88

6 Conrad SA, Rycus PT. Extracorporeal membrane oxygenation in critical care: past, present, and future. J Card Crit Care 2017;1(2):60-64 